\title{
Mechanical Properties of Fly Ash Filled High Density Polyethylene
}

\section{Iftekhar Ahmad and Prakash A. Mahanwar}

Department of Polymer Engineering and Technology, Institute of Chemical Technology, Mumbai University, Mumbai 400019, India

*Corresponding Author:pmahanwar@yahoo.com

\begin{abstract}
Effect of fly ash as filler in mechanical properties of HDPE is described in this study. Three different particle size of fly ash was used. Concentration of fly ash was varied up to $40 \%$ by weight. The composites were prepared using twin screw extruder and then test specimens were prepared by injection molding. Tensile, flexural and impact properties were tested. The microstructure was investigated through scanning electron microscopy (SEM) of the fractured samples. Both tensile and flexural strengths and moduli were found to increase with fly ash addition. Tensile elongation drastically reduced at fly ash concentration greater than $10 \%$. With increasing fly ash concentration impact resistance decreased up to about 15\% fly ash concentration and then did not reduce significantly on further addition. Composites with smallest size fly ash particles proved to be better in enhancing strength and relative elongation. Modulus and impact resistance did not seem to depend much on particle size.
\end{abstract}

Key words: composites; fly ash; mechanical properties; polyethylene.

\section{INTRODUCTION}

In order to reduce the production cost of plastic products, and to improve certain characteristics, one or more fillers are usually used as an addition to the resin matrix. The total production of fly ash in India was approximately 111 million tons in 2004-05. About half of the fly ash is used in cement and brick industries and for landfill purposes. Due to reduce environmental concerns and disposal difficulties, the utilization of fly ash has become of great importance. Some studies have pointed to the excellent compatibility between fly ash and polymers. ${ }^{1-3}$ Other researches have 
also shown the advantageous use of treated fly ash in a wide variety of polymer matrices. ${ }^{4-8}$ Although incidental success stories are published, a systematic approach on investigating the influence of fly ash on polymer properties for the various different polymer types and the enormous amount of possible formulations has not yet been properly undertaken. As a part of an attempt into this direction, the present work deals with HDPE-fly ash composites. Various mechanical properties of the composites were evaluated. Attempts have also been made to correlate them. The properties shown by the composites will help in estimating their suitability for various applications.

\section{EXPERIMENTAL}

\subsection{Materials}

Injection grade HDPE (M60075) was supplied by Reliance Industries Limited, having density of $0.960 \mathrm{~g} / \mathrm{cm}^{3}$ and MFI of $8.2 \mathrm{~g} / 10 \mathrm{~min}\left(190^{\circ} \mathrm{C}, 2.16 \mathrm{~kg}\right)$. Fly ash was supplied by NTPC, Farakka (West Bengal, India). Physical properties of the fly ash are tabulated in Table 1. Table 2 shows general chemical composition of fly ash.

Table 1. Physical properties of the fly ash used.

\section{Physical Properties}

\begin{tabular}{ll}
\hline Density, g/cm & \\
Bulk Density, g/cm & 2.17 \\
Moisture content, \% & 1.26 \\
& 2 \\
Particle Shape & Spherical/ \\
& Irregular \\
Color & Grey \\
\hline
\end{tabular}

Table 2. General chemical composition of fly ash (from Handbook of fillers ${ }^{9}$ ).

\section{Chemical Composition}

\begin{tabular}{ll}
\hline $\mathrm{SiO}_{2}$ & $30-60 \%$ \\
$\mathrm{Al}_{2} \mathrm{O}_{3}$ & $11-19 \%$ \\
$\mathrm{Fe}_{2} \mathrm{O}_{3}$ & $4-11 \%$ \\
$\mathrm{MgO}$ & $5-6 \%$ \\
$\mathrm{CaO}$ & $2-45 \%$ \\
& $\mathrm{Na}, \mathrm{B}, \mathrm{K}, \mathrm{St}, \mathrm{Ba}$ \\
Trace elements & $\mathrm{Mo}, \mathrm{Li}, \mathrm{Vd}, \mathrm{Cr}$ \\
\hline
\end{tabular}




\subsection{Preparative Methods}

Fly ash was washed with water, dried and passed through various sieves. The three grades of particle sizes selected were:

1) particles that passed through sieve with cell diameter of 45 microns (B.S.S. 350),

2) particles collected between sieves with cell diameters of 45 microns (B.S.S 350) and 53 microns (B.S.S. 300), and,

3) particles collected between sieves with cell diameters of 63 microns (B.S.S. 240) and 90 microns (B.S.S. 170).

Fly ash particles were then oven-dried for $15 \mathrm{hrs}$ at $100^{\circ} \mathrm{C}$ to reduce its moisture content. These grades were labeled as 14, 22 and 50 microns respectively according to their volume weighted mean. HDPE-fly ash composites were prepared with varying concentrations of fly ash, viz., 5, 10, 15, 20, 30 and 40\% (by wt.) using co-rotating twin-screw extruder (MP19PC APV Baker, UK). The temperature set points were $130^{\circ} \mathrm{C}, 150^{\circ} \mathrm{C}, 170^{\circ} \mathrm{C}, 190^{\circ} \mathrm{C}$ and $200^{\circ} \mathrm{C}$ respectively from feed zone to die zone, RPM was set around 50 for unfilled and lightly filled systems. The value of RPM was reduced down to 20 while compounding $30 \%$ and $40 \%$ filled composites. Efforts were made to keep the RPM constant, though some fluctuations prevailed. The L/D ratio of the extruder was $25: 1$. Feed rate was around $25 \mathrm{~g} / \mathrm{min}$. The extrudates were water cooled at room temperature, and then granulated.

The granules were then fed to injection molding machine (Boolani Engineering Corporation) of $150 \mathrm{~kg} / \mathrm{cm}^{2}$ capacity to prepare test specimens. The mold was designed as per ASTM standards to produce specimens for tensile, flexural and impact tests. Weight of each shot required was around $30 \mathrm{~g}$. Barrel temperature set points of rear zone, middle zone and nozzle zone were $130^{\circ} \mathrm{C}$, $180^{\circ} \mathrm{C}$ and $200^{\circ} \mathrm{C}$ respectively. For $30 \%$ and $40 \%$ fly ash filled systems, temperatures of middle and nozzle zones required to increase by $10^{\circ} \mathrm{C}$. First stage injection pressure was applied for $4 \mathrm{~s}$ and varied from $90 \mathrm{~kg} / \mathrm{cm}^{2}$ for unfilled HDPE to $115 \mathrm{~kg} / \mathrm{cm}^{2}$ for $40 \%$ fly ash filled HDPE. Second stage pressure and back pressure were kept at $110 \mathrm{~kg} / \mathrm{cm}^{2}$ and $90 \mathrm{~kg} / \mathrm{cm}^{2}$ for $3 \mathrm{~s}$ and $2 \mathrm{~s}$ respectively. Screw speed was set to $240 \mathrm{rpm}$ and injection speed was around $1 \mathrm{~m} / \mathrm{s}$. The samples of HDPE composites prepared by injection molding were kept at room temperature for $48 \mathrm{hrs}$ prior to testing to promote relaxation of stress.

\subsection{Measurements}

Particle sizes distributions of the different grades of fly ash were analyzed using Hydro 2000MU (A), Malvern Instruments Ltd. Water was used as dispersing medium. The distributions obtained are shown in Figure 1. Volume weighted average $\left(d_{4,3}\right)$ of the samples were found to be 14.364 $\mu \mathrm{m}, 22.149 \mu \mathrm{m}$ and $50.062 \mu \mathrm{m}$ respectively. 


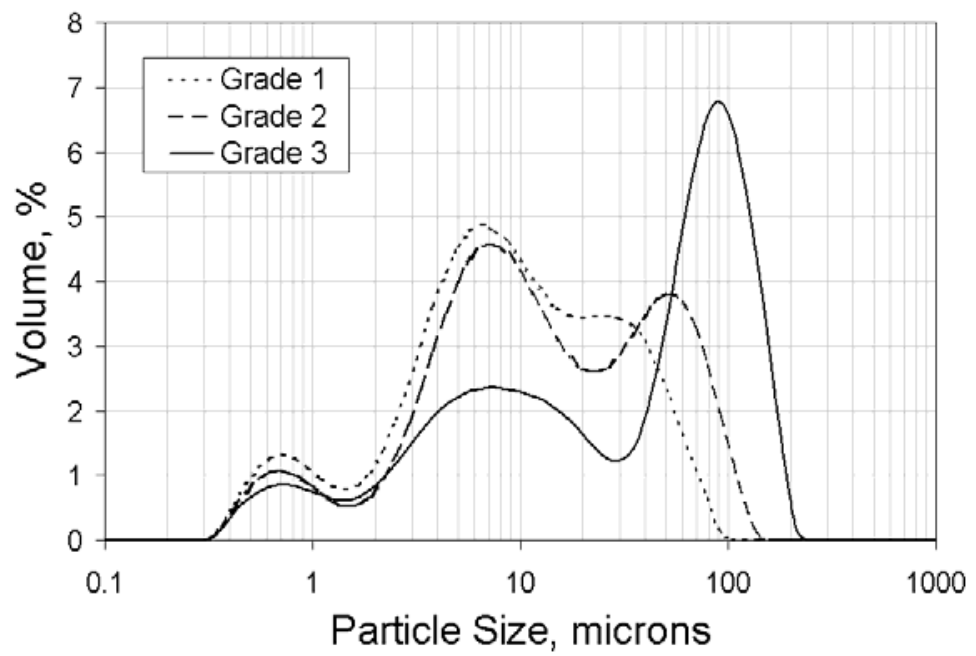

Figure 1. Particle size distribution of the various grades of fly ash used.

Tensile and flexural properties were tested as per ASTM D638 and D790 respectively using universal tensile tester (LR 50k, Lloyd Instruments Ltd.). Specimens for tensile tests were specified according to type-IV (ASTM D638-03). Tensile properties were checked at speed of 50 $\mathrm{mm} / \mathrm{min}$. Load cell of $5 \mathrm{kN}$ was used to sense the load. Five test specimens of each composite were tested and their average value was calculated. Tensile strength at yield, elongation at break and moduli of elasticity were determined. Procedure A was followed to carry out the flexural tests. Width and depth of specimen were 12.5 and $6.5 \mathrm{~mm}$ respectively, support span length of $100 \mathrm{~mm}$ was selected, and rate of crosshead motion was kept at $2.8 \mathrm{~mm} / \mathrm{min}$. All samples of HDPE composites exhibited yielding behavior. Three specimens of each composite were tested and their average value was reported. Flexural strength and tangent modulus values were evaluated.

Izod impact properties were determined as per ASTM D256, method A, using Avery Denison impact tester with pendulum capacity of $2.7 \mathrm{~J}$. Dimensions of depth and width of the specimens were $13 \mathrm{~mm}$ by $13 \mathrm{~mm}$. These specimens were subjected to notch cutter for making notches prior to impact test. Impact resistance was determined by taking average of five test specimens.

SEM images of the impact fractured surface of the composites were also obtained using JEOL (JSM-6380), at an accelerated voltage of $15 \mathrm{kV}$.

\section{RESULTS AND DISCUSSION}

Addition of fly ash in HDPE made the melt more viscous. It also made processing difficult requiring higher temperature and more injection pressure. However, as expected, shrinkage ratio of the composite decreased with increasing fly ash content. 
The density of the composite increased with fly ash concentration. Particle size distribution of various grades of fly ash and the various mechanical properties of the composites prepared are discussed below.

\subsection{Particle Size Distribution of Various Grades of Fly Ash}

The volume weighted mean of second and third grades of fly ash were expected in between the cell diameters of the used sieves, but were found to be much less. This was because of the presence of smaller particles (below about 20 microns) in substantial amount, as is obvious from Figure 1. The fly ash sample was somewhat sticky in nature and was not free flowing. This might have hindered the passage of the smaller particles into the next sieves of smaller cell diameters. Thus a fraction of the smaller particles remained in all the three grades. The agglomerates of these smaller particles dispersed in water when sonicated before being analyzed for particle size distribution, thus making the smaller particles available for detection.

The particle size distributions of the first and second grades differ only slightly. This was again because of the presence of considerable amount smaller particles below 20 microns in both the grades. However, the distribution of second grade showed a grater fraction of larger particles as revealed by the peak around 50 microns.

Because of the stickiness of the fly ash sample, separation of grades was not possible with the help of electric shakers alone. Therefore, after electric shaking, they were subjected to manual shaking. This long course of shaking might have increased the diameters of some sieve cells thus allowing the larger particles to pass through them. Thus we can find from Figure 1, a fraction of oversized particles in each grade.

\subsection{Tensile Properties}

The tensile property of unfilled HDPE specimen was characteristic of cold drawing polymer. During the test, yielding was accompanied with the formation of neck in the region of gauge length. The molecular chains get highly oriented in the stressed neck region. Elongation up to $810 \%$ was obtained. At fracture, fibrillation occurred. This necking behavior was also observed in cases of 5\% and $10 \%$ fly ash filled HDPE, but for lower elongations. The strengths of the necks of filled systems were lesser than that of unfilled HDPE. This could be attributed to poor filler matrix adhesion. Thus it could be inferred that fly ash can produce deleterious effects while preparing polyethylene filaments.

Addition of fly ash increased the strength and modulus but elongation experienced a setback. A typical stress-strain plot has been shown in Figure 2(a) for unfilled HDPE and its composites with 
fly ash at various concentrations. The initial region of the plot has been expanded and shown in Figure 2(b) to get a better idea of stresses at yield and initial slopes of the curves.
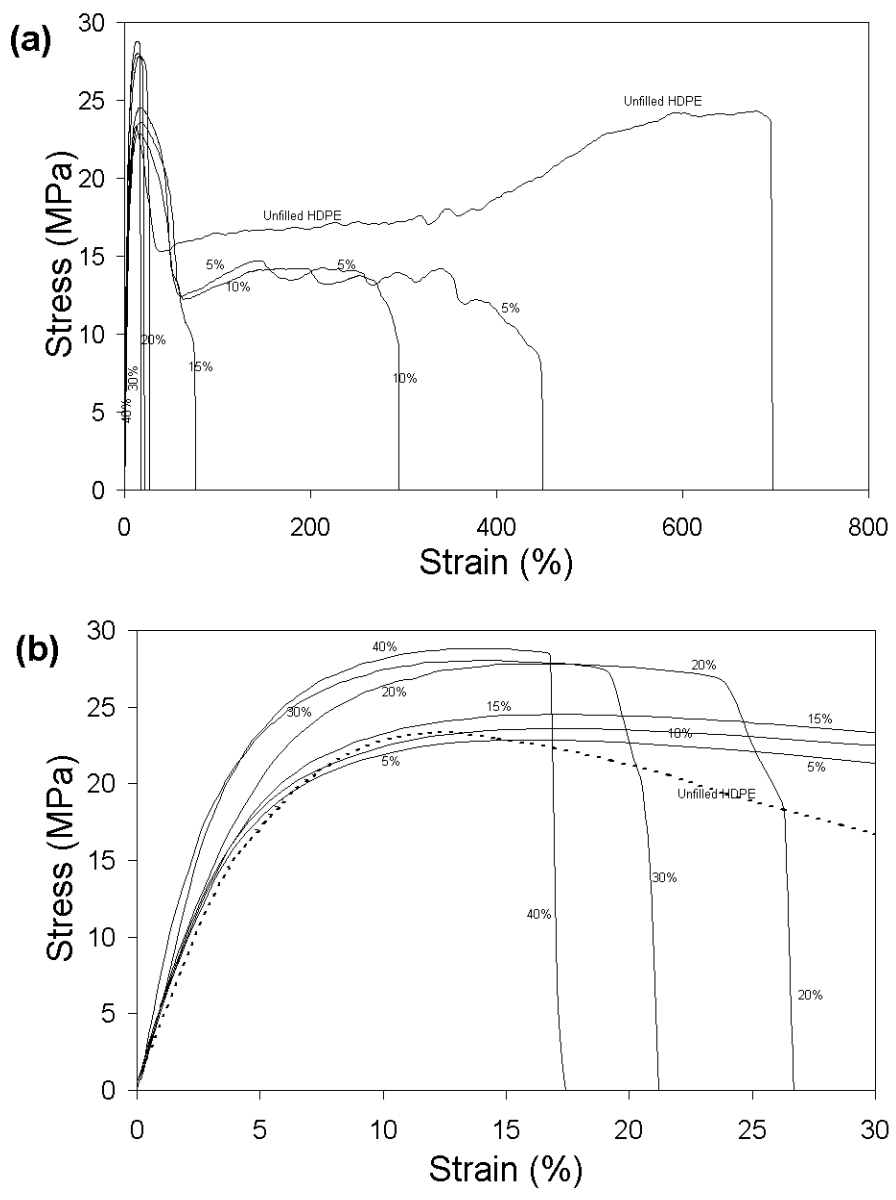

Figure 2. (a) Stress vs. strain curves for unfilled HDPE and its composites with fly ash at various concentrations. (b) Initial region of the stress-strain curve.

The stress-strain curve for the unfilled HDPE showed the maximum stress at break whereas the filled systems showed maximum stress at yield. This was because of high orientation of HDPE molecules in the neck region when subject to high strain. To get this effect in the composites as well, de-bonding of fly ash particles should not occur before the ductile elongation of the HDPE matrix. Also, further matrix elongation at higher strain values should not be hindered by fly ash particles. For this, it requires bond strength between filler and matrix to be higher than the strength required for the ductile elongation of matrix, so that the ductile elongation is not interrupted by de-bonding of filler which leads to void formation.

Initially the curves were smooth up to about $150 \%$ strain after which they showed occasional fluctuations because of breakage of fibrils at different extensions leading to final breakdown. 
This has been depicted diagrammatically in Figure 3. Thus, we can observe in Figure 2(a) that there was no sudden break in the cases of unfilled HDPE and its composites with 5\% and 10\% fly ash. Whereas, in the cases of highly filled HDPE, sudden break was observed.

(a)

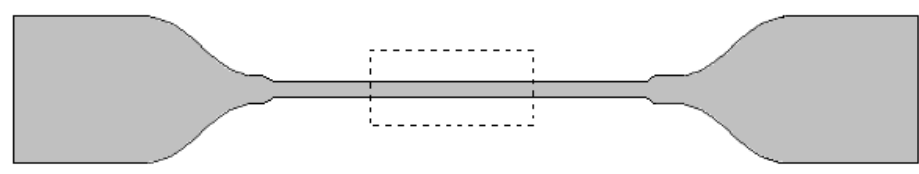

(b)

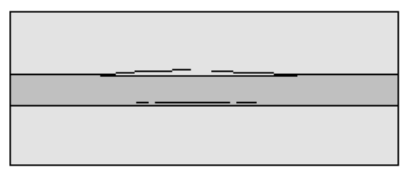

(c)

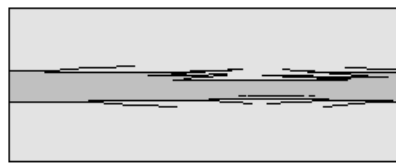

Figure 3. Mechanism of breakage of fibrils in the elongated neck of tensile specimen: (a) formation of neck in the region of gauge length, (b) occasional breakage of fibrils at higher strains, (c) breakage of fibrils leading to tensile failure.

The SEM image in Figure 4 revealed formations of voids at the fly ash-matrix interfaces. When elongated these voids coalesce and lead to fracture or break. The void concentration increased with fly ash concentration thus reducing the elongation at break. The SEM image in Figure 5(a) gave an idea of the mechanism of tensile failure which is depicted diagrammatically in Figure 5(b). The SEM image also revealed that small fly ash particles (less than about $3 \mu \mathrm{m}$ ) did not play significant role in bringing about the fracture. Thus we can expect to get longer elongations by using fly ash particles of size less than $3 \mu \mathrm{m}$.

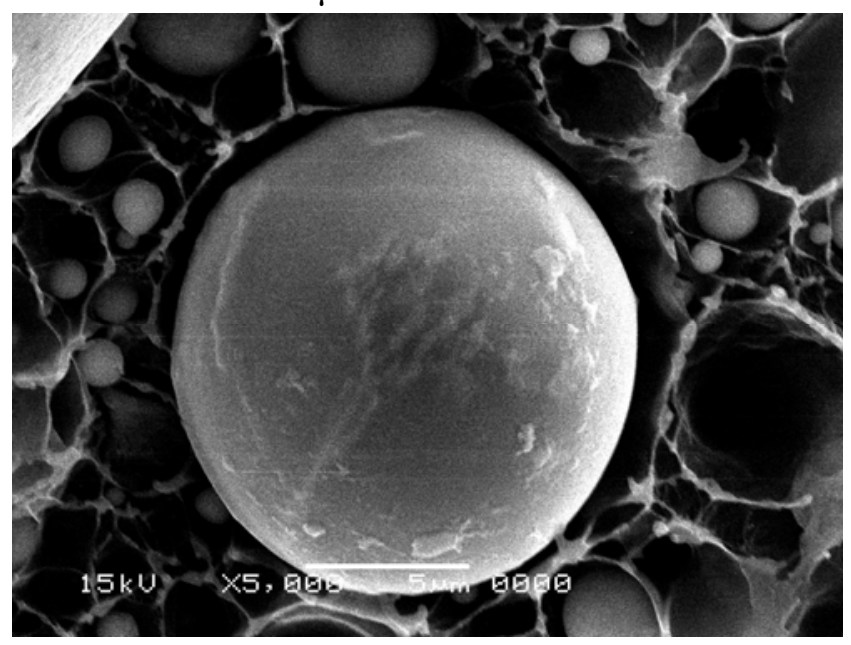

Figure 4. SEM image of $40 \%$ fly ash filled HDPE at magnification of 5000X. 


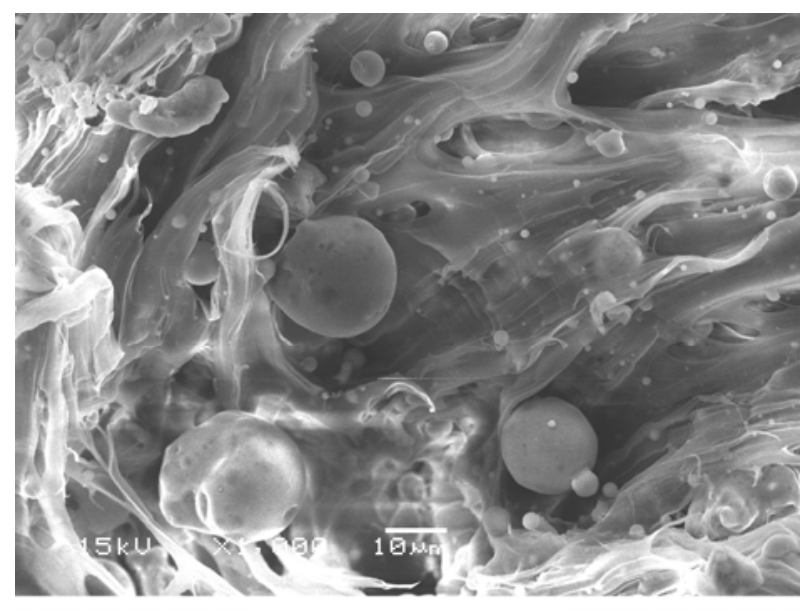

(a)

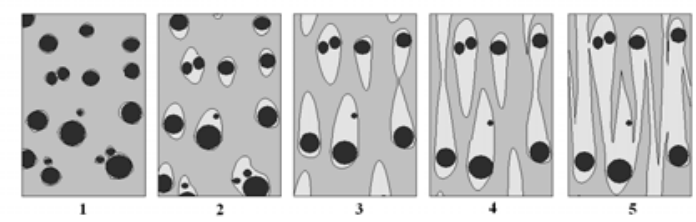

(b)

Figure 5. (a) SEM image of tensile fractured surface at 1000X showing the mechanism of failure.

(b) Schematic representation of steps involved in tensile fracture.

Tensile strength vs. fly ash concentration curves were plotted and depicted in Figure 6(a). These curves did not follow any smooth pattern probably due to the non-homogeneous dispersion of fly ash particles in polymer matrix. Addition of fly ash improved tensile yield strength but only at certain concentrations. Improvements up to $22 \%$ were found from about $23.60 \mathrm{MPa}$ to $28.79 \mathrm{MPa}$. In the case fly ash particles with greatest size (50 micron), strength was found even to get reduced by up to $4 \%$. Tensile strengths did not change much with fly ash concentrations up to $10-15 \%$. Significant increase in strength was found with 14 micron and 22 micron fly ash particles when their concentration exceeded $15 \%$. This reflected the contribution made by fly ash particles to impart their own property to the polymer. Thus, strength increased with concentration. This is possible when there is good interaction between fly ash and the matrix. Thus, there must exist some adhesion between them. The SEM image in Figure 4 showed the evidence of some adhesion as we can see some polymer attached to the cleaved surface of fly ash.

In case of fly ash particles with smallest size (14 micron), increased surface area might have allowed for better filler-matrix interaction thus increasing the chances to enhance the strength. However, in some compositions of 22 and 50 micron, improvements in tensile strength were very small and in some cases even got reduced. This might be because of reduced surface area, 
and, ineffectiveness of fly ash particles as stress-bearing centers and might, in fact, provided loci for stress release.
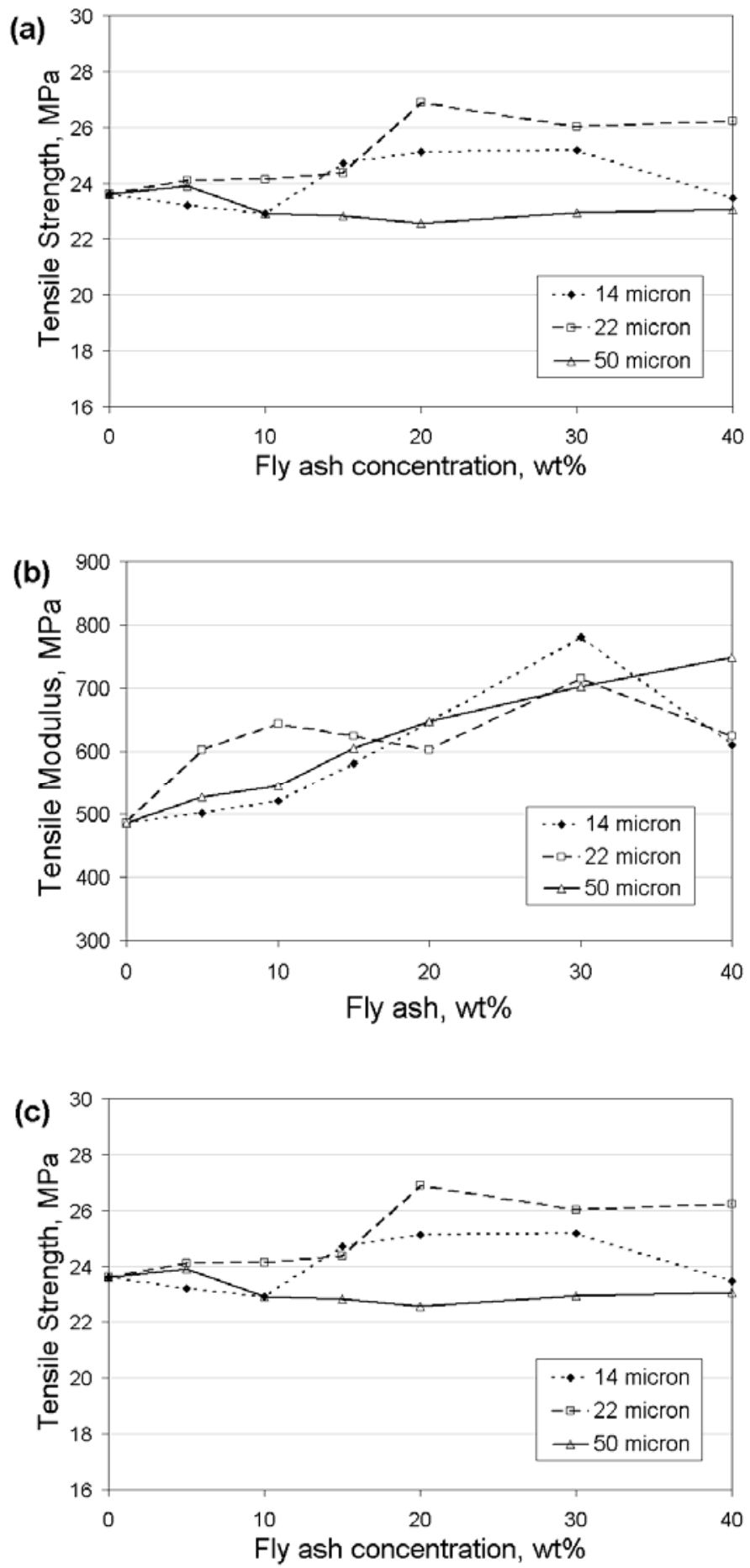

Figure 6. (a) Tensile strength vs. fly ash concentration of HDPE-fly ash composites for different particle sizes of fly ash. (b) Tensile modulus vs. fly ash concentration of HDPE-fly ash composites for different particle sizes of fly ash. (c) Extension at break vs. fly ash concentration of HDPE-fly ash composites for different particle sizes of fly ash. 
Tensile modulus vs. fly ash concentrations was plotted as shown in Figure 6(b). Tensile modulus increased with fly ash concentration up to about $160 \%$ from $486 \mathrm{MPa}$ to about $781 \mathrm{MPa}$. This supports the earlier study of Pukanszky et al. ${ }^{10}$ that strength of the interaction hardly influences the modulus. This is because modulus is a phenomenon involving very small strain values. Small stresses are produced by application of small values of strain. Such small stresses are not sufficient even to break the weak interactions at the interface. Thus these small stresses can easily be transferred from matrix to filler thus allowing the filler to contribute its high modulus property to the composite.

Particle size also did not seem to affect the modulus. However, fluctuations in the values of modulus were observed. These fluctuations were more for highly filled HDPE as is obvious from high standard deviation values shown in Table 3. Non-homogeneity might be a reason for these fluctuations which became pronounced in cases of highly filled systems.

Table 3. Standard deviations for tensile properties of HDPE and its composites with fly ash.

\begin{tabular}{|c|c|c|c|c|c|c|c|c|c|}
\hline \multirow{2}{*}{$\begin{array}{c}\text { Composition } \downarrow \\
\text { Unfilled HDPE }\end{array}$} & \multicolumn{3}{|c|}{$\begin{array}{l}\text { Std. Dev. of } \\
\text { Tensile Strength, } \\
\text { MPa }\end{array}$} & \multicolumn{3}{|c|}{$\begin{array}{l}\text { Std. Dev. of } \\
\text { Tensile Modulus, } \\
\text { MPa }\end{array}$} & \multicolumn{3}{|c|}{$\begin{array}{l}\text { Std. Dev. of } \\
\text { Elongation, \% }\end{array}$} \\
\hline & & 0.93 & & & 25 & & & 52 & \\
\hline Avg. Particle Size $\rightarrow$ & $14 \mu$ & $22 \mu$ & $50 \mu$ & $14 \mu$ & $22 \mu$ & $50 \mu$ & $14 \mu$ & $22 \mu$ & $50 \mu$ \\
\hline HDPE $:$ Fly ash = 95:05 & 1.79 & 1.33 & 0.48 & 24 & 19 & 8 & 32 & 67 & 55 \\
\hline HDPE : Fly ash = 90:10 & 0.45 & 1.10 & 0.40 & 16 & 15 & 23 & 40 & 166 & 14 \\
\hline HDPE $:$ Fly ash $=85: 15$ & 0.89 & 0.78 & 0.89 & 46 & 55 & 22 & 5 & 4 & 13 \\
\hline HDPE $:$ Fly ash $=80: 20$ & 0.40 & 1.10 & 0.51 & 56 & 46 & 15 & 0.2 & 11 & 13 \\
\hline HDPE $:$ Fly ash $=70: 30$ & 0.74 & 1.70 & 1.00 & 7 & 166 & 15 & 0.6 & 5 & 1.3 \\
\hline HDPE $:$ Fly ash $=60: 40$ & 1.04 & 4.04 & 0.90 & 60 & 91 & 176 & 0.4 & 19 & 7 \\
\hline
\end{tabular}

There was drastic reduction in ultimate elongation from about $810 \%$ to about $77 \%$ and less when fly ash concentration went above $15 \mathrm{wt} \%$ as shown in Figure 6(c). Amongst the three particle sizes, 14 micron, which was the smallest of them all, showed somewhat longer relative elongations up to $15 \mathrm{wt} \%$ fly ash. Thus it might be possible to get greater elongations by further reducing the particle size. Also, Figure 5(a) showed that matrix separation had been originated at the interface of large fly ash particles, and, no separation of matrix around small particles. As the specimen is elongated, there would be a stress transfer from the polymer to the fly ash through the interface if interfacial bondage is good. Thus, poor interfacial bond might be the reason for lower elongation. There were void formations at the fly ash-matrix interface. When elongated these voids coalesced and lead to fracture or break. The void concentration increased with fly ash concentration thus reducing the elongation at break. With increase in particle size the void size also increased resulting in earlier failure and this might be the cause of poor relative elongation for higher particle 
sizes. Another possible reason is the higher surface area provided by smaller particles for interacting with the matrix polymer.

Table 4. Standard deviations for flexural and impact properties of HDPE and its composites with fly ash.

\begin{tabular}{|c|c|c|c|c|c|c|c|c|c|}
\hline \multirow{2}{*}{$\begin{array}{l}\text { Composition } \downarrow \\
\text { Unfilled HDPE }\end{array}$} & \multicolumn{3}{|c|}{$\begin{array}{l}\text { Std. Dev. of } \\
\text { Flexural Strength, } \\
\text { MPa }\end{array}$} & \multicolumn{3}{|c|}{$\begin{array}{l}\text { Std. Dev. of } \\
\text { Flexural Modulus, } \\
\text { MPa }\end{array}$} & \multicolumn{3}{|c|}{$\begin{array}{l}\text { Std. Dev. of } \\
\text { Impact Strength, } \\
\text { MPa }\end{array}$} \\
\hline & & 0.35 & & & 47 & & & 9.05 & \\
\hline Avg. Particle Size $\rightarrow$ & $14 \mu$ & $22 \mu$ & $14 \mu$ & $22 \mu$ & $50 \mu$ & $50 \mu$ & $14 \mu$ & $22 \mu$ & $50 \mu$ \\
\hline HDPE $:$ Fly ash $=95: 05$ & 0.25 & 0.17 & 116 & 214 & 40 & 0.55 & 4.56 & 5.00 & 4.79 \\
\hline HDPE $:$ Fly ash $=90: 10$ & 0.11 & 0.29 & 68 & 97 & 40 & 0.30 & 2.56 & 1.73 & 3.56 \\
\hline HDPE $:$ Fly ash $=85: 15$ & 0.42 & 1.15 & 51 & 131 & 223 & 1.01 & 4.35 & 4.19 & 1.68 \\
\hline HDPE : Fly ash $=80: 20$ & 0.61 & 0.96 & 131 & 120 & 240 & 0.22 & 1.32 & 1.27 & 1.46 \\
\hline HDPE : Fly ash $=70: 30$ & 1.60 & 0.84 & 67 & 63 & 142 & 0.32 & 3.22 & 0.41 & 1.10 \\
\hline HDPE : Fly ash $=60: 40$ & 0.53 & 0.61 & 69 & 119 & 157 & 0.41 & 4.13 & 0.48 & 3.36 \\
\hline
\end{tabular}

\subsection{Flexural Properties}

A typical stress-strain behavior of HDPE and its composites has been depicted in Figure 7. Strength as well as modulus can be found to increase with fly ash concentration. Unfilled HDPE showed a somewhat linear curve as compared to filled systems which were much curvilinear. This appeared to be because of increased modulus contributed by the fly ash particles and thus increasing the initial slope of the curve. But at higher strain, weak filler-matrix interaction resulted in slippage and cleavage of the interface, thus deviating curve from linear characteristic. Here again, modulus appeared not to depend much on filler-matrix interaction.

Figures 8(a) and (b) present the variation in flexural strength and flexural modulus with varying concentrations of fly ash of different particle sizes. It was observed that flexural strength increased as fly as concentration increased. The increase becomes more pronounced when concentration went above $10 \%$. A maximum of about $25 \%$ increase was observed from $17.3 \mathrm{MPa}$ for unfilled HDPE to about $21.6 \mathrm{MPa}$ for $40 \%$ fly ash filled HDPE. This could be attributed to the contribution provided by the high strength fly ash particles, thus strength increased with increasing concentration of fly ash. This again, is only possible if there is stress transfer from matrix to filler through a fairly strong interfacial bond. Bond cleavage leading to failure is not obtained in bending test as the maximum strain applied is only of 5\%. From Figure 2(a), it could be inferred that 5\% strain was insufficient to cause a failure. Thus here, in the case of flexural strength, interfacial interaction between fly ash particles and HDPE matrix had only served to transfer stress. Further improvement in strength might be brought about by increasing the fly ash concentration beyond 40 wt $\%$. 


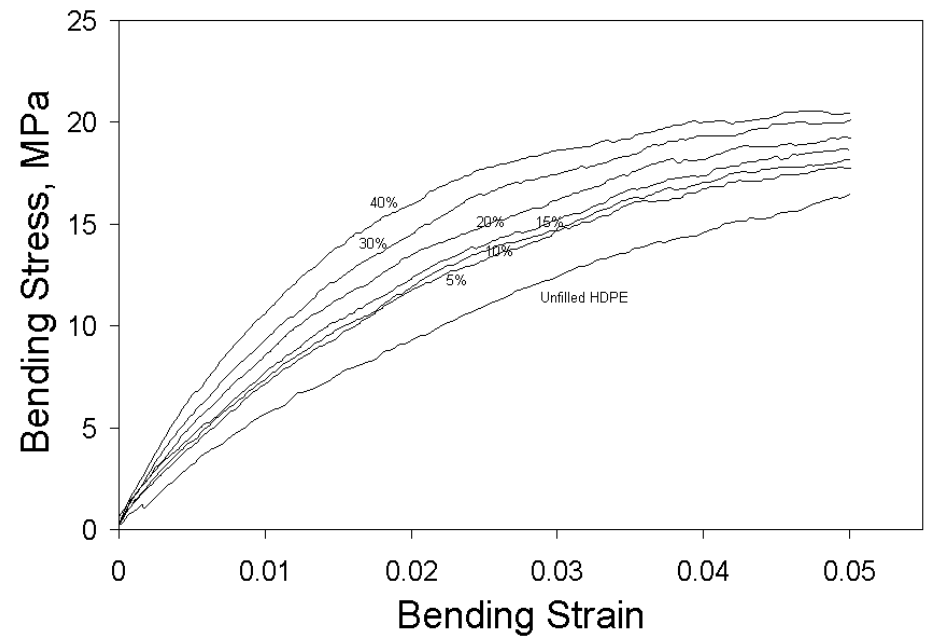

Figure 7. Typical stress-strain plot of HDPE and its composites with fly ash obtained by bending test.
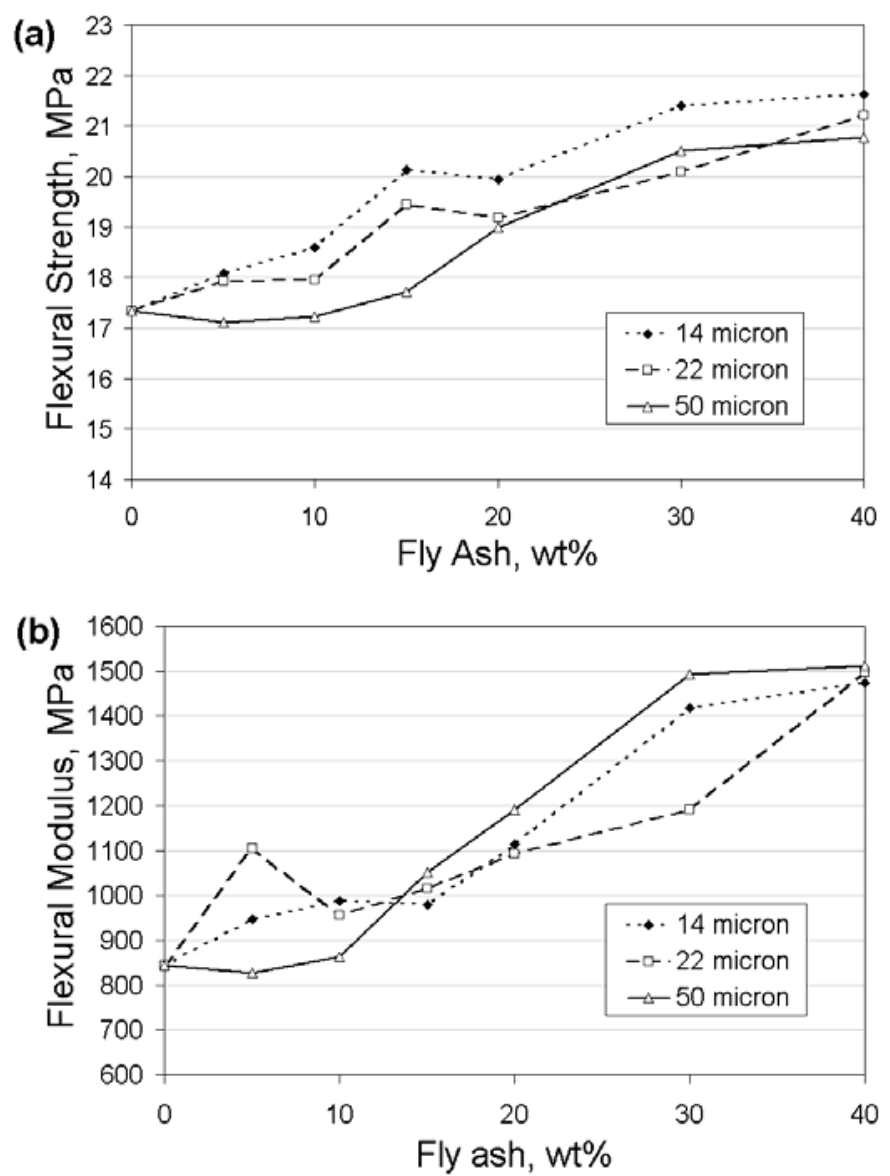

Figure 8. (a) Flexural strength vs. fly ash concentration of HDPE-fly ash composites for different particle sizes of fly ash. (b) Flexural modulus vs. fly ash concentration of HDPE-fly ash composites for different particle sizes of fly ash. 
The smallest particle size (14 micron) used showed better strength at all concentrations. This might be because of increased surface area exposed for interaction. Thus we can expect to further increase the strength by using further small size of fly ash particles.

As expected, flexural modulus was found to increase with increasing fly ash concentration. Again, this could be attributed to the contribution made by the fly ash particles to impart its own property to the composite. The curve in Figure 8(b) revealed that initially there was around 13\% improvement in modulus up to $15 \%$ fly ash concentration. The increase in modulus became pronounced for concentrations greater than $15 \%$. Maximum modulus of about $1600 \mathrm{MPa}$ was achieved at $40 \%$ fly ash concentration which amounted to about $80 \%$ more than unfilled HDPE. The greatest particle size ( 50 micron) showed greater increase in modulus at higher concentrations, but had lower modulus at concentrations below $15 \%$.

\subsection{Impact Properties}

Figure 9 depicts the Izod impact resistance of the HDPE - fly ash composites. There was gradual reduction in impact resistance as the fly ash content increased, and was not much affected by particle size. This reduction seemed to get saturated after $20 \%$ fly ash for the higher particle sizes of 22 and 50 microns. The rate of reduction was high at lower concentrations of fly ash, which might be because of formation of additional voids due to greater mold shrinkage during cooling of injection molded specimens. This shrinkage was highly reduced for higher concentrations of fly ash, especially, when above $20 \%$.

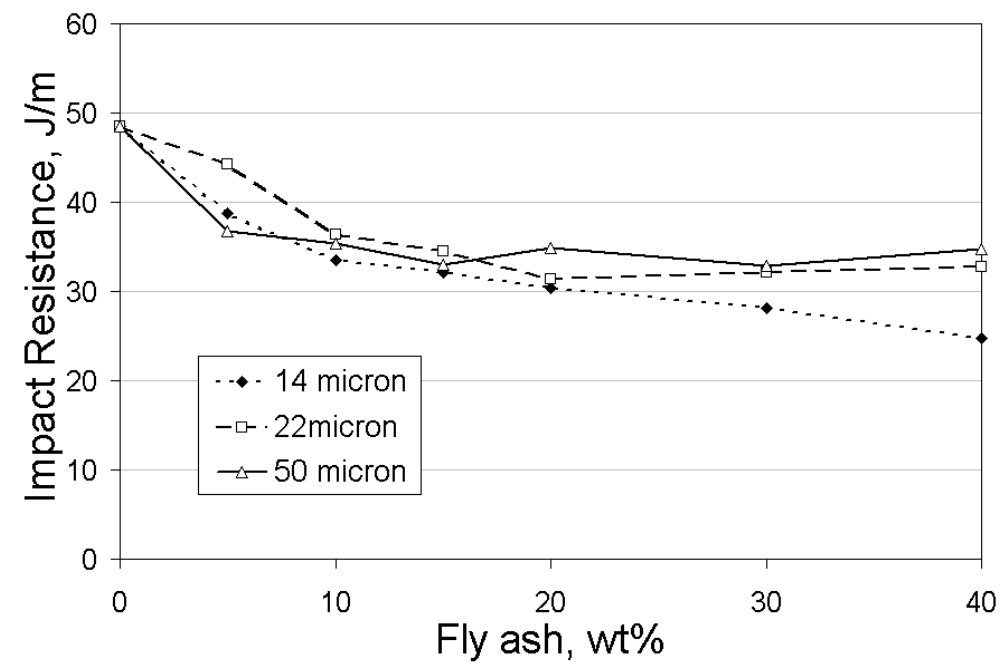

Figure 9. Impact resistance vs. fly ash concentration of HDPE-fly ash composites for different particle sizes of fly ash. 
SEM image of the impact fractured surface of $40 \%$ fly ash filled HDPE has been shown in Figures 10 (a) and (b). The image evidenced crack formation at the fractured surface itself. Such secondary cracks are expected at high concentrations of fly ash. Additional energy was absorbed as these secondary cracks were generated thus contributing to the overall impact resistance of the composites. These secondary cracks along with primary crack might be another reason for not allowing further reduction of impact resistance at filler concentrations above $20 \%$.

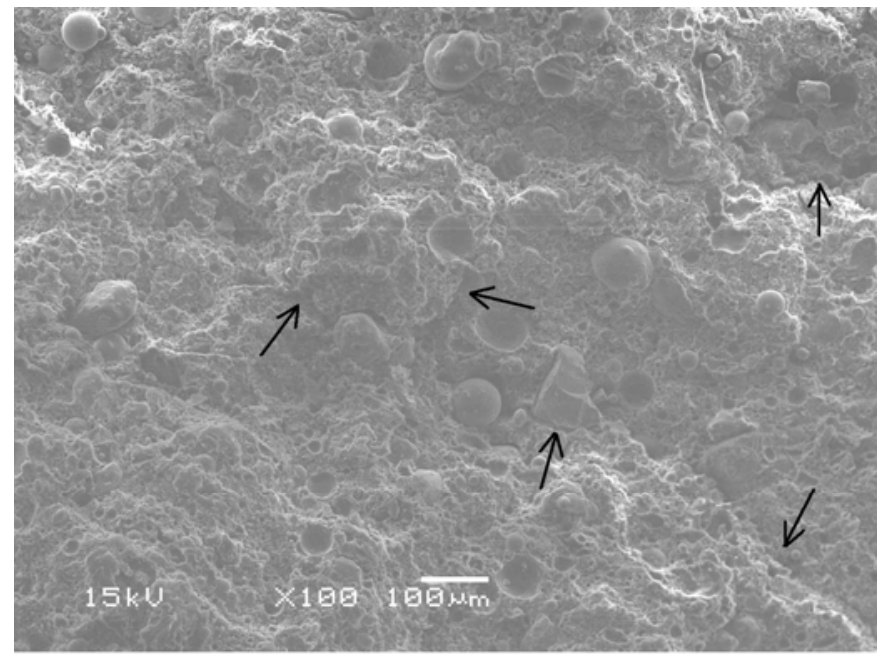

(a)

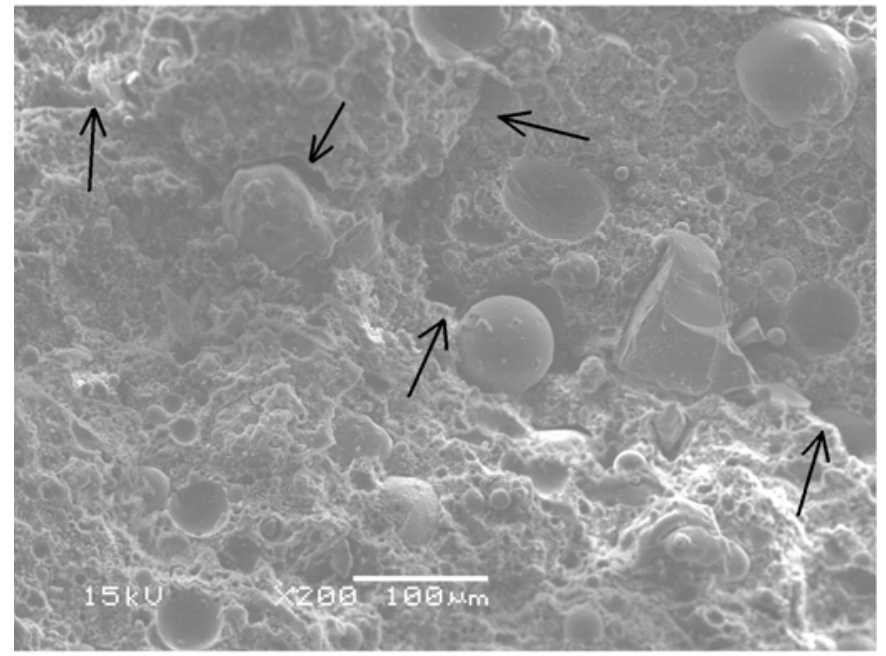

(b)

Figure 10. (a) SEM image of impact fractured sample of $40 \%$ fly ash filled HDPE showing secondary fractures as trenches in the matrix (100X), (b) The same image at higher magnification (200X). 


\section{CONCLUSIONS}

Tensile strength could be increased by up to $22 \%$ by using $14 \mu \mathrm{m}$ fly ash particles. Better strength might be expected by using further reduced size of fly ash particles. Tensile modulus increased with fly ash concentration with about $160 \%$ increase at $40 \%$ filler. Further increase might be obtained at concentrations greater than $40 \%$. Modulus was found not do depend much on particle size.

Addition of fly ash may exhibit deleterious effects on the ductile property of polyethylene used for making filaments. However, the ductile property can be expected to retain to some extent when fly particle of size less than $3 \mu \mathrm{m}$ is used. Non-homogeneous dispersion may also result in premature failure of composites especially in highly filled composites.

Flexural strength and flexural modulus were found to increase with fly ash concentration by up to $25 \%$ and $80 \%$ respectively. Finest particles showed best flexural strength at all concentrations.

With fly ash addition, impact resistance gradually decreased by about $35 \%$ up to $20 \%$ filler concentration. At higher concentrations further reduction was checked probably by generation of secondary cracks.

To increase impact strength, suitable surface modification or coupling is required which may bring about some strong chemical bond between filler and matrix. This may also help to improve the tensile and flexural strength still further. But again, these additives will increase the processing steps and cost of the finished product. However, the untreated fly ash filled HDPE may find applications in making low cost products such as wire and cable coatings, pipes, drums, chairs, crates and in flooring.

Experiments with surface modified fly ash has been done and is expected to be published later.

\section{ACKNOWLEDGEMENTS}

The authors would like to thank Reliance Industries Ltd. for providing HDPE, and, National Thermal Power Corporation of India (N.T.P.C.), Farakka (W.B.) for providing fly ash used to carry out the research.

\section{REFERENCES}

1. Hodd, K. A.; Davies, L. C. B.; Sothern, G. R. Proceedings Second International Conference on Ash Technology and Marketing, London, September 1984, 647-51. 
2. Plowan, C.; Shaw, N. C. Proceedings Second International Conference on Ash Technology and Marketing, London, September 1984, 663-70.

3. O'Keeffe, J. Proceedings Second International Conference on Ash Technology and Marketing, London, September 1984, 653-62.

4. Huang X.; Hwang J. Y.; Gillis J. M.; Proceedings 12th International Symposium on Coal Combustion by-product Management and Use, 1997, 22.

5. Guhanathan S.; Devi M. S.; Murugeshan V.; Journal of Applied Polymer Science, 2000, 82, 1755-1760.

6. Alkan C.; Arslan M.; Cici M.; Kaya M.; Aksoy M. Resourses, Conservation and Recycling, 1995, 13, 147-154.

7. Bose S.; Mahanwar P. A.; Journal of Minerals and Materials Characterization and Engineering, 2004, 3, 2, 65-72.

8. Hundiwale D. G.; Kapadi U. R.; Desai M. C.; Patil A. G.; Bidkar S. H.; Polymer-Plastics Technology and Engineering, 2004, 43, 3, 615-630.

9. Wypych G. Handbook of Fillers, 2nd ed.; Chem Tec Publishing, Toronto, 2000; Chap. 2.

10. Pukanszky, B.; Fekete, E.; Tudos, F. Makromol. Chem. Macromol. Symp., 1989, 28, 165. 